\title{
Bone abnormalities and severe arthritis in pachydermoperiostosis
}

\author{
R G Cooper, A J Freemont, M Riley, P J L Holt, D C Anderson, M I V Jayson
}

University of

Manchester,

Rheumatic Diseases

Centre, Hope Hospital,

Salford, United Kingdom

R G Cooper

M I V Jayson

University of

Manchester,

Department of

Medicine

(Endocrinology),

Hope Hospital, Salford,

United Kingdom

D C Anderson

University of

Manchester,

Department of

Radiology,

Manchester Royal

Infirmary, Oxford Road,

Manchester,

United Kingdom

M Riley

University of

Manchester,

Department of

Rheumatology,

Manchester Royal

Infirmary, Oxford Road,

Manchester,

United Kingdom

P J L Holt

University of

Manchester,

Bone Disease

Research Centre,

Manchester,

United Kingdom

A J Freemont

D C Anderson

Correspondence to:

Dr R G Cooper,

Rheumatic Diseases Centre,

University of

Manchester,

Mope Hospital,

Hope Hospital,

Eccles Old Road,

Salford M6 8HD,

Accepted for publication

18 June 1991

\begin{abstract}
Two patients with pachydermoperiostosis were studied in whom the predominant features at presentation were severe and disabling knee and ankle joint pain in association with distal long bone pain. Analysis of synovial fluid from the knee joints showed non-inflammatory changes. In one patient a bicortical iliac crest bone biopsy specimen, taken after labelling with demeclocycline, showed appositional rates which were increased in cortical bone but reduced in trabecular bone. This mismatching resulted in trabecular osteoporosis, which occurred in association with increased numbers of osteoclasts, findings which suggest differential functional changes affecting the two bony envelopes.
\end{abstract}

Pachydermoperiostosis, or primary hypertrophic osteoarthropathy, was first described in $1935 .{ }^{1}$ It is an inherited disease which is autosomal dominant with variable penetration and it is phenotypically more severe in men. The disease is characterised clinically by digital clubbing, periostitis, and hypertrophic skin changes (pachydermia), which may cause marked furrowing of the brow, seborrhoea with hyperhidrosis, and arthralgia or arthritis. ${ }^{2-4}$ The onset of symptoms, which is often preceded by symptomless clubbing, is usually during the second decade of life. ${ }^{4}$ Although up to $40 \%$ of patients may develop synovial effusions these are usually symptomless and, if painful, usually respond to non-steroidal anti-inflammatory drugs (NSAIDs). ${ }^{4}$ We report two patients with primary hypertrophic osteoarthropathy in whom bone changes were investigated histologically and in whom severe joint pain was the initial reason for presentation and which was refractory to treatment.

\section{Case reports}

PATIENT 1

In 1971 a healthy 16 year old white boy presented to an endocrinologist with severe joint pain in association with excessive growth. There was no relevant family history. Physical examination showed a tall $(196 \mathrm{~cm})$ adolescent with marked digital clubbing, gross periarticular soft tissue hypertrophy around the wrists, knees, and ankles, and bilateral knee joint effusions. Acromegaly was suspected clinically. Initial investigations showed: haemoglobin 126 $\mathrm{g} / \mathrm{l}$, erythrocyte sedimentation rate $26 \mathrm{~mm} /$ hour, baseline plasma growth hormone $2.6 \mathrm{MU} / \mathrm{l}$ (normal value $<10 \mathrm{MU} / \mathrm{l}$ ) suppressing to $2 \cdot 2$ $\mathrm{MU} / \mathrm{l}$ during a standard glucose tolerance test; chest and skull radiographs were normal. In view of the normal endocrine results, the patient was referred to a rheumatologist. Subsequent investigations showed that IgM rheumatoid factor, antinuclear factor, and lupus erythematosus cells were negative and that plasma calcium, inorganic phosphate and alkaline phosphatase, and serum iron, iron binding capacity, immunoglobulin levels and liver function tests (serum aspartate aminotransferase and serum alanine aminotransferase, and bilirubin) were normal. Twenty four hour urinary calcium excretion was also normal $(4 \cdot 1-5 \cdot 2 \mathrm{mmol})$, but that of hydroxyproline was increased to $35-45 \mathrm{mg} / \mathrm{m}^{2}$ (normal $20 \mathrm{mg} / \mathrm{m}^{2}$ ). A radiological examination showed a periosteal reaction along the distal ulnae, tibiae, and fibulae and a bone scan using labelling with strontium 87 confirmed increased isotope uptake at these sites. A synovial biopsy sample from the right knee showed venous dilatation without inflammation whereas a biopsy sample of skin from the ankle showed gross dermal thickening with hypertrophy of the sweat glands. A biopsy sample of the tibial metaphysis, after labelling with demeclocycline, showed normal osteoid seams with minimal separation of the labelled lines, indicating that the hyperostosis was relatively inactive.

Pachydermoperiostosis was diagnosed, the increased hydroxyproline excretion reflecting the increased metabolic rates of collagen and bone. In view of the severity of the patient's joint pain, which had responded poorly to treatment with NSAIDs, a trial with high doses of corticosteroids was thought to be justified (enteric coated prednisolone, $50 \mathrm{mg} /$ day) and the effects were monitored biochemically using the excretion levels of urinary hydroxyproline. These decreased towards normal values rapidly but the symptoms continued intermittently and improved only gradually. By 1979 the patient still had disabling joint pain and his 24 hour urinary hydroxyproline excretion was still raised, at $32 \mathrm{mg} / \mathrm{m}^{2}$, but he was now working full time and the prednisolone, which had been gradually reduced, was discontinued. The patient subsequently continued to have joint symptoms, which were not progressive, and he remains otherwise well.

\section{PATIENT 2}

In 1989 a 17 year old healthy white boy developed severe pain and swelling of his knees and ankles after playing football. There was no 
relevant family history. The joints did not settle with rest. Rheumatological examination revealed a healthy patient with marked digital clubbing and an inflammatory arthritis affecting his knees and ankles with bilateral knee joint effusions. As a testicular swelling was also found, a paramalignant syndrome was suspected and a testicular exploration was performed and a biopsy sample taken; the histology was normal. Other investigations with normal results included haemoglobin, erythrocyte sedimentation rate, IgM rheumatoid factor, antinuclear factor, a chest radiograph, and computed tomography examination of the abdomen. Treatment with an NSAID was begun, but gave little symptomatic relief, and two months later the patient developed severe upper abdominal pain. A perforated duodenal ulcer was confirmed on admission to hospital and vagotomy and pyloroplasty were performed. The NSAID was

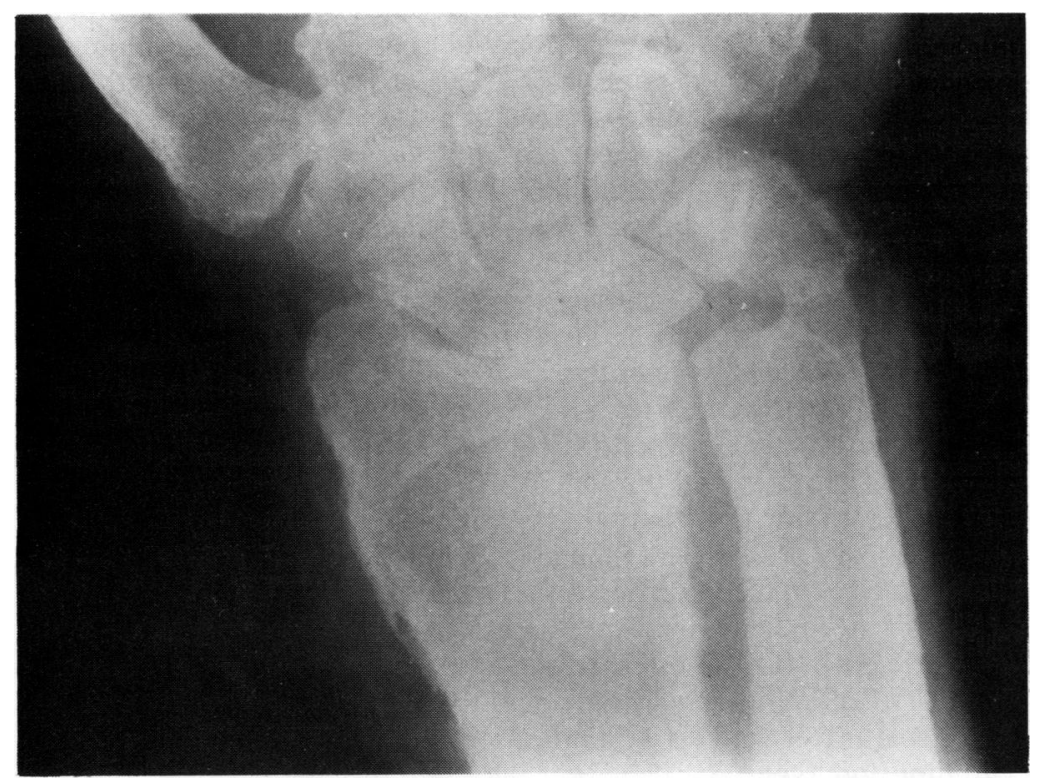

Figure 1 Plain radiograph of the wrist of patient 1. Periosteal reaction is seen along the distal radius and ulnar extending across the arrested growth plate and onto the epiphysis, a feature thought to be specific for primary hypertrophic osteoarthropathy anly. ${ }^{1 /}$

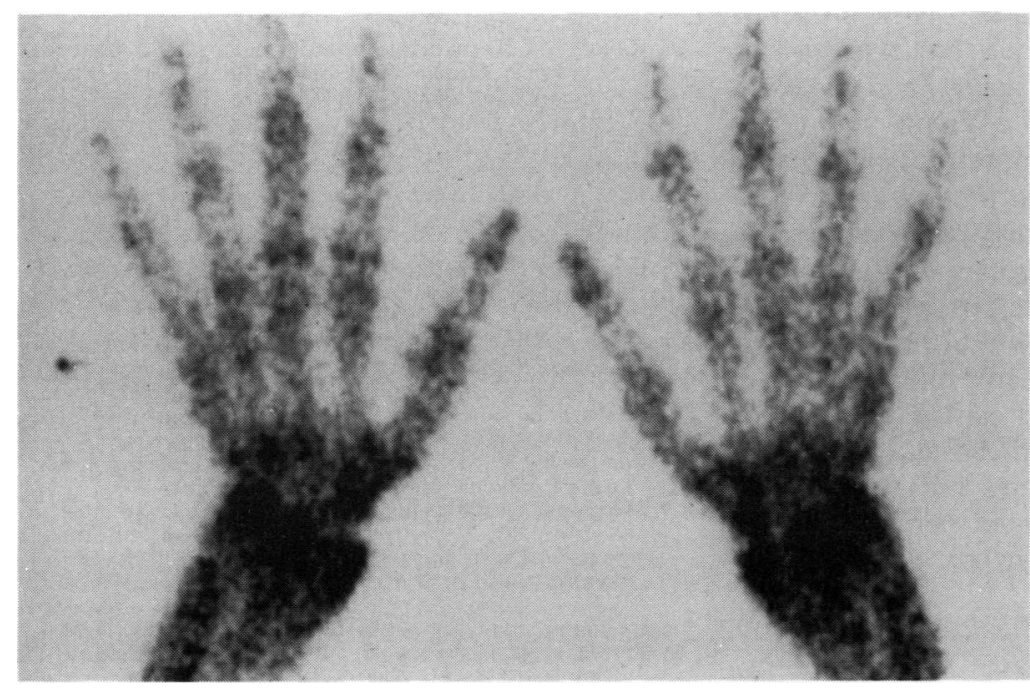

Figure 2 Bone scan of patient 2 using bisphosphonate labelled with technetium, showing markedly increased uptake in the distal radius and ulnar. This was not due to the epiphysial growth plate, which was fused on plain radiographs. withdrawn and treatment with sulphasalazine was begun, but without success. In view of the severity of his continued problems, which had precluded his finishing A level and business degree studies, a second rheumatological opinion was sought.

The patient now also described hyperhidrosis with 60 minutes of morning stiffness and pain affecting the small joints of his fingers and toes. His general health remained good, his weight was steady, and his bowel action normal. Physical examination now showed synovitis of the proximal and distal interphalangeal joints of his fingers and toes, and tender bony swellings of the distal radius, ulna, tibia, and fibula bilaterally. Further investigations showed a baseline growth hormone level of $2 \cdot 8 \mathrm{MU} / \mathrm{l}$, decreasing to $0.5 \mathrm{MU} / \mathrm{l}$ (normal $<10$ ) during a glucose tolerance test. A chest radiograph was normal. Examination of the synovial fluid showed a very low white cell count $\left(100 / \mathrm{mm}^{3}\right)$ which was within the normal range. Unusually, however, the predominant cell was densely stained with non-specific esterase-that is, the cells were macrophages. This contrasts with normal subjects in whom synoviocytes predominate. In all other aspects the fluid resembled that of a non-inflammatory arthropathy. Radiographs of his hands, feet, femora, and pelvis showed exuberant periosteal deposition of new bone (fig 1) and a bone scan using labelling with technetium confirmed increased uptake in the distal ends of his limb long bones (fig 2). A small bowel enema and duodenal biopsy sample were normal. A full thickness iliac crest bone biopsy sample, following labelling with demeclocycline, showed hyperactive cortical bone deposition, but with marked trabecular osteoporosis in association with increased numbers of osteoclasts (fig 3, table). A diagnosis of pachydermoperiostosis was made.

As the patient's joint symptoms were severe and persistent a trial of high dose prednisolone

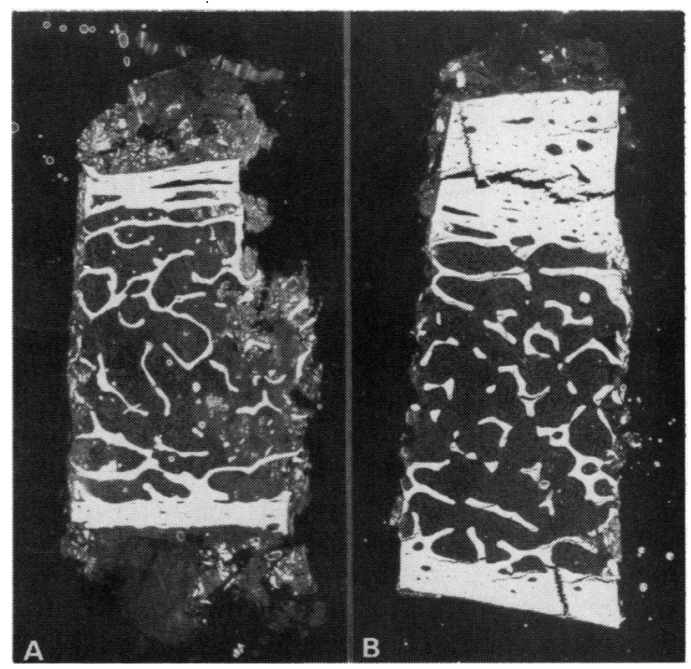

Figure 3 Reverse prints of full thickness, bicortical bone biopsy specimens from the posterior iliac crests of (A) a normal subject and $(B)$ patient 2 . The outer cortices lie at the bottom of the print in both instances. A comparison of the biopsy specimens showed markedly thickened cortices, especially the inner cortex, in patient 2, but with trabecular thinning as a result of relative osteoporosis. 
Histomorphometric results for trabecular and cortical bone from patient 2. Results for normal controls given as mean $(S D)$

\begin{tabular}{|c|c|c|}
\hline Histomorphometric findings & Patient 2 & $\begin{array}{l}\text { Normal age and } \\
\text { sex matched } \\
\text { controls }(n=10)\end{array}$ \\
\hline $\begin{array}{l}\text { Trabecular bone volume (\%) } \\
\text { Total osteoid surfaces (\%) } \\
\text { Total resorptive surfaces }(\%) \\
\text { Mineralising seams }(\%) \\
\text { Osteoclast count }\left(/ \mathrm{mm}^{2}\right)\end{array}$ & $\begin{array}{l}16 \cdot 1 \\
20 \cdot 0 \\
5 \cdot 0 \\
81 \cdot 4 \\
0 \cdot 467\end{array}$ & $\begin{array}{l}23 \cdot 1(4 \cdot 5) \\
18 \cdot 2(5.4) \\
3.6(1.7) \\
76.9(12 \cdot 4) \\
\text { Median } 0.045 \\
\text { (range } 0.001- \\
0.196)\end{array}$ \\
\hline $\begin{array}{l}\text { Appositional rate }(\mu \mathrm{g} / \mathrm{day}) \\
\text { Trabecular bone } \\
\text { Cortical bone }\end{array}$ & $\begin{array}{l}0.44 \\
1 \cdot 17\end{array}$ & $0.70(0.12)$ \\
\hline
\end{tabular}

was begun empirically. This provided little relief except when given in doses in excess of $20 \mathrm{mg}$, and was therefore discontinued. Intraarticular steroid injections did not help. The patient is currently trying to return to his business degree studies.

\section{Discussion}

Hypertrophic osteoarthropathy was first described during the late nineteenth century in association with severe lung infections, ${ }^{56}$ but has since been regarded an ominous clinical sign portending bronchial and other neoplasms. Digital clubbing occurs in most patients with hypertrophic osteoarthropathy ${ }^{7}$ and the two abnormalities occur in similar thoracoabdominal diseases, ${ }^{8}$ including congenital cyanotic heart disease and cystic fibrosis. 9 10 ${ }^{\text {The skeletal }}$ morphological abnormalities seen in clubbing and hypertrophic osteoarthropathy are identical,' suggesting a common cause.

In recent reviews of clubbing and hypertrophic osteoarthropathy, neurogenic and hormonal causative mechanisms were suggested. ${ }^{11}$ The 'neurogenic theory' proposes that afferents arising from diseased internal organs travel via the vagus nerve and induce clubbing and hypertrophic osteoarthropathy by reflex, whereas the 'hormonal theory' proposes that hormone-like substances, capable of inducing clubbing and hypertrophic osteoarthropathy, are normally present in plasma but are inactivated during pulmonary passage. In patients with bronchogenic carcinomas, tumour derived hormone-like substances can presumably gain direct access to the systemic circulation. ${ }^{11}$ Where shunts or direct systemic access do not result from serious internal disorders, such as in primary hypertrophic osteoarthropathy, an overproduction of hormone-like substances is proposed. ${ }^{12}$ Whatever the composition of the putative hormonelike substances, and growth hormone abnormalities appear to have been excluded, ${ }^{13}$ their effects are widespread and can be detected in dermal and epidermal endothelial and connective tissues. Wide field nail bed microscopy also shows capillary dilatation and periungual skin histology shows endothelial hyperplasia, hyalinosis, and sclerosis. ${ }^{14} 15$

In primary hypertrophic osteoarthropathy synovial fluid studies have shown non-inflammatory microscopic appearances whereas synovial histological examinations show hypercellularity and vascular thickening, but with- out inflammation. ${ }^{10}$ Radiological studies have indicated that, for primary and secondary hypertrophic osteoarthropathy alike, the degree of periosteal reaction depends on the duration of the disease rather than its cause. ${ }^{17}$ There are no previous reports of bone histology in primary hypertrophic osteoarthropathy. Our results, summarised in the table and fig 3 , indicated a trabecular osteoclast count an order of magnitude greater than that seen in normal bone, in combination with a reduced appositional rate which contrasts with an increased appositional rate in cortical bone. This mismatching of osteoclast and osteoblast activity appears to be the cause of reduced trabecular bone mass, despite normal osteoid thickness, combined with markedly increased cortical bone mass in both Haversian and periosteal new bone. These findings suggest differential functional changes affecting the two bony envelopes which has not been shown previously.

The natural history of primary hypertrophic osteoarthropathy appears to be self limiting, an active adolescent phase being followed by a quiescent adult phase. ${ }^{12}$ Our first patient fits this pattern well as, at 35 years of age, his symptoms are considerably reduced, even though the pain and disability were severe during the active phase of his disease. The second patient remains a problem with respect to treatment because of the severity of his symptoms, and his difficulties in tolerating drugs given by mouth. These patients highlight the difficulties in treating patients when symptoms are severe. The known data indicate that the associated joint problem is noninflammatory, so the use of systemic steroids is difficult to justify, especially considering the expected natural history of primary hypertrophic osteoarthropathy. Indeed, the trabecular osteoporosis presently shown possibly represents a contraindication.

We gratefully acknowledge the assistance of $\mathrm{J}$ B Weiss, who performed the hydroxyproline assays, including establishing a normal reference range in the required age group.

1 Touraine A, Solente G, Gole L. Un syndrome osteodermopathique: la pachydermie plicaturee avec pachyperiostose pathique: la pachydermie plicaturee avec pach
des extremities. Presse Med 1935; 43: 493-504.

2 Rimoin D L. Pachydermoperiostitis (idiopathic clubbing and periostitis). Genetic and physiological considerations. N Engl F Med 1965; 272: 924-31.

3 Martinez-Lavin M, Pineda C, Valde\% T, et al. Primary hypertrophic osteoarthropathy. Semin Arthritis Rheum 1988; 17: 156-62.

4 Vogl A, Goldfischer S. Pachydermoperiostitis: primary or idiopathic hypertrophic osteoarthropathy. Am 7 Med 1962; 33: 166-87.

5 Bamberger E. Ueber knockenveranderungen bei chronischen lungenund herzkrankheiten. Z Klin Med 1891; 18: 193217.

6 Marie P. De L'osteoarthropathie hypertrophiante pneumonique. Rev Med (Paris) 1890; 10: 1-36.

7 Locke E. Secondary hypertrophic osteoarthropathy and its relation to simple club fingers. Arch Intern Med 1915; 15: 659-77.

8 Mendlowitz M. Clubbing and hypertrophic osteoarthropathy. Medicine (Baltimore) 1942; 21: 269-306.

9 Martine $\%$-Lavin M, Bobadilla M, Casanova J, Ahie F, Martine' M. Hypertrophic osteoarthropathy in cyanotic congenital heart disease. Arthritis Rheum 1982; 25: 1186-93.

10 Cohen A, Yulish B, Wasser K, Vignos P J, Jones P K, Sorin $\mathrm{S}$ B. Evaluation of pulmonary hypertrophic osteoarthropathy in cystic fibrosis. Am $\mathcal{Y}$ Dis Child 1986; 140: 74-7.

11 Pineda C J, Guerra J Jr, Weisman M H, Resnick D, Martine\%-Lavin $M$. The skeletal manifestations of clubMartine\%-Lavin $M$. The skeletal manifestations of club-
bing: a study of patients with cyanotic congenital heart disease and hypertrophic osteoarthropathy. Semin Arthritis Rheum 1985; 14: 263-73.

12 Martinez-Lavin M. Digital clubbing and hypertrophic osteo- 

arthropathy: a unifying hypothesis. $\mathcal{F}$ Rheumatol 1987; 14:
6-8.

13 Dupont B, Hoyr I, Borgestov S, Nerup J. Plasma growth hormone and hypertrophic osteoarthropathy in carcinoma of the bronchus. Acta Med Scand 1970; 188: 25-30.

14 Matucci-Cerinic M, Cinti S, Morroni M. Pachydermoperiostitis (primary hypertrophic osteoarthropathy): report of a case with evidence of endothelial and connective tissue involvement. Ann Rheum Dis 1989; 48: 240-6.

15 Matucci-Cerinic M, Lotti T, Jajic I, Lollo D, Brunetti L, Orlic D. Cutaneous fibrinolytic activity in primary hyper- trophic osteoarthropathy. Scand J Rheumatol 1987; 16: $205-12$.

16 Lauter S, Vasey F, Huttner I, Osterland C K. Pachydermoperiositis. Studies on the synovium. I Rheumatol 1978; 5: 88-9.

17 Pineda C J, Martinez-Lavin M, Goobar J E, Sartoris D J, Clopton P, Resnick D. Periostitis in hypertrophic osteoarthropathy: relationship to disease duration. Am $\mathcal{J}$ Radiol 1987; 148: 773-8.

18 Resnick D. In: Resnick D, ed. Bone and foint Imaging. London: Saunders, 1989: 1239-41. 